\title{
KEBUTUHAN DASAR MANUSIA DALAM PERSPEKTIF PENDIDIKAN ISLAM
}

\author{
Heru Juabdin Sada \\ herujuabdin@radenintan.ac.id \\ Universitas Islam Negeri Raden Intan Lampung
}

\begin{abstract}
Needs are something that is needed by humans to reach the level of well-being, so that if human needs are not met properly, then their human beings will not feel prosperous. It can be said that needs are something that must be there, because without that our lives become less prosperous or at least less prosperous. There are five basic human needs as stated by Abraham Maslow, the need for self-actualization, self-esteem needs, the need for love and the need for affection, the need for security and the need for comfort and need. In Islam, looking at the most basic human needs is an absolute obligation that must be lived and fulfilled among them needs: Dharuriyat Needs ( $i$ ) the need to maintain religion: hold fast to religion, learn it, then preach it, stay away and warn of shirk and riya '; Combating apostates; Reminiscent of bid'ah actions and against ahlul bid'ah. (ii). self-care needs: in an emergency (forced), can eat any food for survival, even though only something that is available at the origin is available; Fulfill basic basic needs, such as food, drinks and clothing; (iii) moral requirements. (iv) guarding offspring; Prompts for marriage; witness in marriage; must maintain and provide for the child, the obligation to ensure children's education; Forbid marriage with adulterers; Forbid thalaq unless forced and forbid ikhtilâth. (v) safeguarding property: Islam requires Muslims to do charity and endeavor; Maintain property in their power; Islamic religion advocates for bershadaqah, justifying buying and selling and debts; Islamic religion forbids all forms of tyranny against other Muslim rights and property and must replace them; Obligation to safeguard property and not waste it.
\end{abstract}

Keywords: Basic human needs, Islamic education

\begin{abstract}
Abstrak
Kebutuhan merupakan sesuatu yang sangat dibutuhkan oleh manusia untuk mencapai tingkat kesejahteraan, sehingga jika kebutuhan manusia tersebut tidak terpenuhi dengan baik maka manusia mereka merasa tidak sejahtera. Dapat dikatakan bahwa kebutuhan adalah suatu hal yang harus ada, karena tanpa itu hidup kita menjadi tidak sejahtera atau setidaknya kurang sejahtera. Ada lima Kebutuhan mendasar manusia sebagaimana yang di kemukakan oleh Abraham Maslow, Kebutuhan Aktualisasi diri, Kebutuhan harga diri, Kebutuhan akan rasa cinta serta kebutuhan akan rasa sayang, Kebutuhan akan rasa aman dan kebutuahn rasa nyaman dan Kebutuhan. Dalam Islam memandang kebutuhan paling dasar manusia merupakan kewajiban mutlak yang harus dijalani dan dipenuhi diantaranya kebutuhan: Kebutuhan Dharuriyat ( i) kebutuhan menjaga Agama: Berpegang teguh dengan agama, mempelajarinya, lalu mendakwahkannya, Menjauhi dan memperingatkan dari perbuatan syirik dan riya'; Memerangi orang-orang yang murtad; Mengingatkan dari perbuatan bid'ah dan melawan ahlul bid'ah. (ii).kebutuhan menjaga diri: dalam kondisi darurat (terpaksa), dapat memakan makanan apa saja demi bertahan hidup, walaupun yang tersedia hanya sesuatu yang diharam pada asalnya; Memenuhi kebutuhan mendasar dasar diri, seperti makanan-makanan, minuman serta pakaian; (iii) kebutuhan akhlaq. (iv) menjaga keturunan; Anjuran melakukan pernikahan; menjadi saksi
\end{abstract}


dalam pernikahan; wajib memelihara dan memberikan nafkah anak, kewajiban memastikan pendidikan anak; Mengharamkan pernikahan dengan pezina; Melarang thalaq kecuali terpaksa serta Mengharamkan ikhtilâth. (v) menjaga harta: agama Islam mewajibkan muslim beramal dan berusaha; Memelihara harta yang dalam kekuasaan mereka; Agama Islam menganjurkan untuk bershadaqah, menghalalkan jual beli dan hutang-piutang; Agama Islam mengharamkan semua bentuk kezhaliman terhadap hak dan harta muslim lainya dan wajib menggantinya; Kewajiban menjaga harta dan tidak menyia-nyiakannya.

Kata kunci: Kebutuhan dasar manusia, Pendidikan Islam

\section{PENDAHULUAN}

Hidup dalam masyarakat adalah sebuah pilihan, tentunya banyak konsekuensi muncul, bahkan tidak luput dari berbagai macam kendala-kendala sosial yang terjadi dalam masyarakat tersebut. Hal ini tidak terlepas dari banyak "pemain" yang berusaha berspekulasi agar proses sosial yang terjadi tidak mengarah kepada dinamika dan polapola sosial yang sudah terbentuk ratusan tahun. Namun terkadang pola atau interaksi sosial tersebut sering bahkan terkikis karena manusia sebagai bagian dari anggota masyarakat tidak mampu menjalankannya.

Faktor terpenting adalah pola atau interaksi sosial tersebut terkadang tidak pas dengan konteks jaman kekinian, nilai-nilai lama seperti kebersamaan, gotong-royong dan suka tolong-menolong akan semakin terkikis, yang terjadi berkembangnya nilainilai baru yang disebabkan dari adanya pengaruh dari Televisi dan lain sebagainya. Sejauh suasana hidup yang saling mampu dan berkompetisi dunia keseharian tidak lagi diam tetapi semua elemen masyarakat saling memacu untuk mendapatkan status sosial dan pengakuan diri dilingkungan tempat hidupnya.

Oleh karena itulah muncul persoalan demi persoalan baru dalam masyarakat tersebut, misalnya kenyamanan hidup, ketenangan dan keperluan untuk berekreasi. Namun persoalan yang lebih memprihatinkan dalam masyarakat adalah persaingan tidak sehat dalam memenuhi kenyamanan tersebut. Corak baru kehidupan itu telah mulai berkembang. Suatu hal yang tidak bisa dinafikan adalah penggunaan atau penyediaan produk yang sebenarnya tidak dibutuhkan akan tetapi cuma sebagai prestise dan menunjukkan identitas siapa sebenarnya dirinya.

Fenomena tersebut merupakan representasi dari masyarakat yang tidak mempunyai landasan sosial, nilai dan norma masyarakat, kebutuhan hidup itu adalah 
dipandang begitu sakral dan antusiasme yang berlebihan. Dan pada akhirnya mengarah kepada gap atau kesenjangan , kondisi ini lama-lama bisa mengarah kepada caoss/ pertentangan kelas dan pada akhirnya masyarakat tanpa ada nilai, norma atau hidup yang jelas. Semua terjadi diatas pemenuhan demi pemenuhan kebutuhan hidup.

Berdasarkan beberapa penelitian sebelumnya, tbeberapa penlitian telah membahas mengenai kebutuhan kebutuhan dasar manusia maupun kebutuhan lain (Lusianti, 2013; Massie \& Kandou, 2013; Muchtar, 2017; Muryanto, 2016; Rama, 2017; Siska, 2015; Sukwadi, 2013; Supriyanto, 2012; Tekeng \& Alsa, 2016) serta telah dilakukan penelitian dalam meninjau menggunakan perspektif pendidikan islam (Aslan, 2017; Faturrahman, 2016; Hidayati, 2016; Muspiroh, 2016; Najahah, 2016; Qodir, 2014; Ridlwan, 2013; Rifai, 2016; Sukring, 2016; Zainuddin, 2015) Namun penelitian yang membahas kebutuhan dasar manusia dalam perspektif Islam belum pernah dilakukan. Maka, peneliti tertarik untuk melakukan pembahasan mengenai kebutuhan dasar manusia dalam perspektif pendidikan Islam

\section{METODE PENELITIAN}

Jenis penelitian yang digunakan adalah model penelitian kualitatif dengan kajia literatur. Penelitian kualitatif bertujuan memperoleh gambaran seutuhnya mengenai suatu hal menurut pandangan manusia yang diteliti. Penelitian kualitatif berhubungan dengan ide, persepsi, pendapat, atau kepercayaan orang yang diteliti; kesemuanya tidak dapat diukur dengan angka

\section{HASIL KAJIAN DAN PEMBAHASAN}

\section{A. Kebutuhan Manusia}

Kebutuhan merupakan sesuatu yang sangat dibutuhkan oleh manusia untuk dapat mencapai kesejahteraan, sehingga bila kebutuhan tersebut ada yang tidak atau belum terpenuhi maka pastilah manusia akan merasa kurang sejahtera. Dapat dikatakan bahwa kebutuhan adalah suatu hal yang harus ada, karena tanpa itu hidup kita menjadi tidak sejahtera atau setidaknya kurang sejahtera.

1. Model Kebutuhan Dasar Manusia Menurut Beberapa Ahli. 
Abraham Maslow, membagi kebutuhan mendasar manusia dalam lima tingkat yaitu: Kebutuhan fisiologis, yang merupakan kebutuhan paling mendasar dan memiliki tingkat prioritas tertinggi didalam kebutuhan. Kebutuhan fisiologis merupakan hal yang sangat mutlak yang harus terpenuhi oleh manusia untuk mulai bertahan hidup. Kebutuhan tersebut terdiri dari pemenuhan kebutuhan oksigen dan juga pertukaran gas, kebutuhan akan cairan (minuman), kebutuhan akan nutrisi (makanan), kebutuhan akan eliminasi, kebutuhan akan istirahat serta tidur, aktivitas, keseimbangan suhu tubuh, dan kebutuhan akan seksual, kebutuhan kedua adalah Kebutuhan akan adanya rasa aman dan kebutuhan akan perlindungan yang telah dibagi yaitu perlindungan fisik dan juga perlindungan psikologis. Kebutuhan akan rasa cinta dan kasih akan rasa sayang tersebut yaitu kebutuhan untuk dapat memiliki dan dimiliki, antara lain dengan cara memberi dan saling menerima akan rasa kasih sayang, kehangatan, persahabatan, mendapatkan tempat dalam keluarga, suatu kelompok social, kebutuhan akan adanya perasaan dihargai oleh orang lain kebutuhan seperti ini terkait erat dengan adanya keinginan mendapatkan suatu kekuatan, untuk meraih prestasi, mendapatkan rasa yang percaya diri serta kemerdekaan diri. orang juga memerlukan pengakuan dari orang lain, dan yang terakhir/ke lima kebutuhan aktualiasasi diri, merupakan suatu kebutuhan tertinggi dalam hierarki Maslow, berupa suatu kebutuhan untuk ikut serta pada orang lain/lingkungan guna mencapai potensi diri sepenuhnya. Untuk lebih jelas dapat dilihat sebagai berikut berikut:

1. Kebutuhan Aktualisasi diri

2. Kebutuhan harga diri

3. Kebutuhan rasa cinta dan kasih sayang

4. Kebutuhan rasa aman dan nyaman

5. Kebutuhan fisiologis (oksigen, makan, minum, eliminasi, tidur, seks)

\section{B. Konsep Islam Tentang Kebutuhan dasar Manusia}

Dalam Islam, konsumsi tidak bisa dipisahkan dari peranan keimanan. Peranan keimanan menjadi salah satu tolak ukur yang ter penting karena keimanan akan memberikan tentang cara pandang yang cenderung akan mempengaruhi perilaku serta kepribadian manusia. Keimanan sangat mudah mempengaruhi kuantitas dan kualitas 
dari konsumsi baik itu dalam bentuk suatu kepuasan material ataupun bentuk spiritual, yang kemudian mampu membentuk sifat kecenderungan prilaku konsumsi yang ada di pasar. Konsep kebutuhan dalam Islam yaitu bersifat dinamis melihat pada tingkat ekonomi yang ada di masyarakat.

Konsep kebutuhan dasar dalam Islam bersifat sangat dinamis mengacu pada tingkat keadaan ekonomi pada masyarakat. Pada tingkat keadaan ekonomi tertentu barang yang tadinya dikonsumsi karena motivasi keinginan, pada tingkat keadaan ekonomi lebih baik, barang tersebut telah berubah menjadi kebutuhan. Sebagaimana yang di ungkapkan oleh: Al-Syathibi, rumusan kebutuhan manusia dalam Islam terdapat tiga jenjang, yaitu:

\section{Kebutuhan Dharuriyat}

Kebutuhan dharuriyat ialah tingkat kebutuhan primer. Bila tingkat kebutuhan ini tidak terpenuhi, akan terancam keselamatan umat manusia baik di dunia maupun di akhirat kelak. Kebuthan dharuriyat mencakup:

\section{a. Menjaga Din Agama}

Ini merupakan dharûriyyât yang terpenting dan berada pada urutan tertinggi. Sebagaimana firman Allah Subhanahu wa Ta'ala :

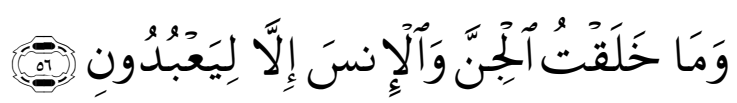

Artinya: dan aku tidak menciptakan jin dan manusia melainkan supaya mereka mengabdi kepada-Ku. (Adz-Dzâriyat 51: 56)

Demikian tujuan hakiki dari penciptaan makhluk. Untuk tercapainya tujuan, maka diutuslah para rasul dan diturunkannya kitab-kitab. Sebagaimana dalam firman-Nya.

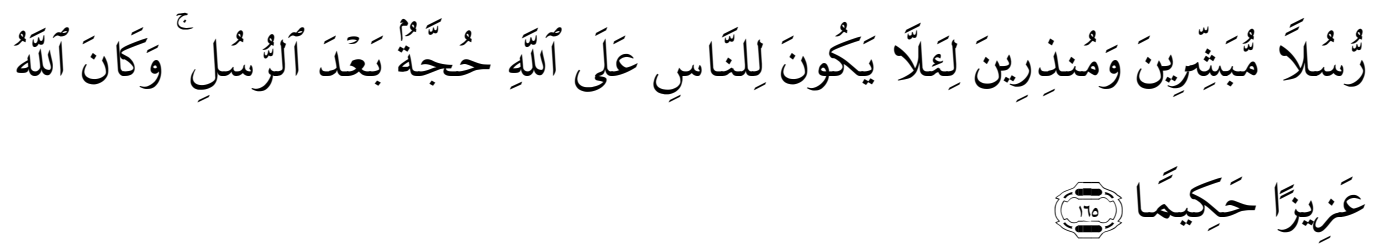


Artinya: "rasul-rasul itu adalah sebagai pembawa berita gembira dan pemberi peringatan agar tidak ada alasan bagi manusia untuk membantar Allah setelah RasulRasul itu diutus, Allah Maha Perkasa lagi Maha Bijaksana.” (An-Nisâ 4: 165).

Begitu juga dengan firman Allah SWT :

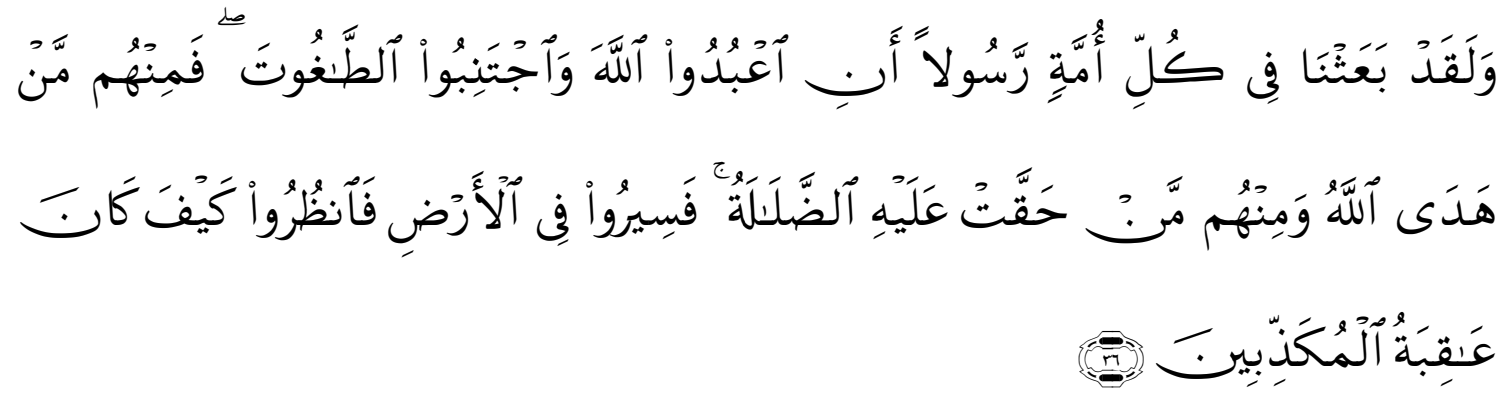

Artinya: dan sungguhnya Kami telah mengutus seorang Rasul untuk setiap umat (untuk menyerukan): "Sembahlah Allah, dan jauhilah Thaghut" kemudian di antara mereka ada yang diberi petunjuk oleh Allah dam ada pula yang tetap dalam kesesatan. Maka berjalanlah kamu di bumi dan perhatikanlah bagaimana kesudahan orang-orang yang mendustakan (rasul-rasul). (An-Nahl $16: 36$ ).

Agar Allah Subhanahu wa Ta'ala menjaga din (agama) dari kerusakan, karena din merupakan dharuriyat yang paling besar dan terpenting, maka syari'at juga mengharamkan riddah (murtad), memberi sanksi kepada orang yang murtad dan dibunuh. Sebagaimana sabda Rasulullah Shallallahu 'alaihi wa sallam :

Hadis nabi yang artinya "Barangsiapa yang mengganti agamanya, maka bunuhlah dia" [HR Bukhari]

Juga sebagaimana sabda beliau Shallallahu 'alaihi wa sallam yang lain.yang artinay "Tidak halal darah seorang muslim (tidak boleh dibunuh, Red.), kecuali dengan salah satu di antara tiga sebab yaitu jiwa dengan jiwa, orang tua yang berzina (dibunuh dengan dirajam, Red.), orang yang murtad meninggalkan agamanya dan jama'ahnya" [HR Bukhari]

\section{b. Menjaga Jiwa (Hifzhun-Nafsi).}


Menjaga jiwa juga termasuk dalam dharûriyatul-khamsi, dan agama tidak akan bisa tegak, kalau tidak ada jiwa-jiwa yang mampu menegakkannya. jika kita ingin mencoba menegakkan din, artinya, kita harus mampu menjaga jiwa-jiwa yang ingin menegakkan agama ini. Untuk menjaga serta memuliakan jiwa-jiwa ini, Allah Azza wa Jalla berfirman :

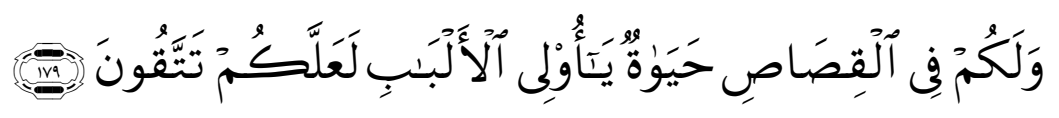

Artinya "Artinya dan dalam qishaash itu ada (jaminan) kehidupan bagimu, wahai orang-orang yang berakal, agar kamu bertakwa." (Al-Baqarah 2:179)

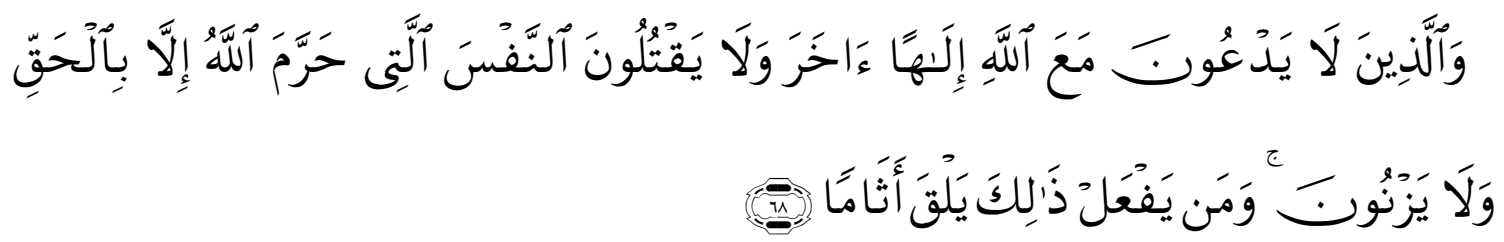

Artinya: "dan orang-orang yang tidak menyembah Tuhan yang lain beserta Allah dan tidak membunuh jiwa yang diharamkan Allah (membunuhnya) kecuali dengan (alasan) yang benar, dan tidak berzina, barang siapa yang melakukan yang demikian itu, niscaya Dia mendapat (pembalasan) dosa(nya). (Al-Furqân 25: 68)

Hifzhun-nafs dapat dilakukan dengan beberapa cara yaitu, di antaranya:

1) Pada saat darurat (sangat terpaksa) ini, wajib memakan apa saja demi keberlangsungan hidup, meskipun yang ada pada saat itu sesuatu yang memang haram pada asalnya.

2) Memenuhi apa saja kebutuhan diri yaitu, berupa makanan, minuman dan pakaian.

3) Mewajibkan pelaksanaan qishash (hukum bunuh bagi siapa yang telah membunuh, jika sudah memenuhi syarat-syaratnya, Red.)

4) dan diharamkan untuk menyakiti atau menyiksa diri (Maqâshidusy-Syarî’ah 'Inda Ibni Taimiyyah, hlm. 462-465.)

\section{c. Menjaga Akal (Hifzhul-Aqli).}

Salah satu sarana untuk menjaga akal yaitu ilmu.Kalimat wahyu yang pertama kali sampai kepada Rasulullah Shallallahu 'alaihi wa sallam dan menyentuh telinga 
Rasulullah Shallallahu 'alaihi wa sallam adalah kalimat iqra' (bacalah!), setelah itu adalah kalimat:

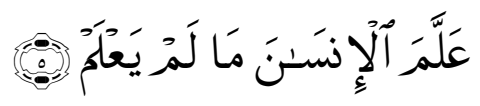

Artinya: "Dia mengajarkan kepada manusia apa yang tidak diketahuinya." (AlAlaq: 96: 5)]

Karena membaca merupakan salah satu jalan untuk mendapatkan ilmu, meskipun bukan dari jalan satu-satunya, akan tetapi merupakan jalan terpenting. Dalam nash Al-Qur'an yang lain, Allah berfirman,

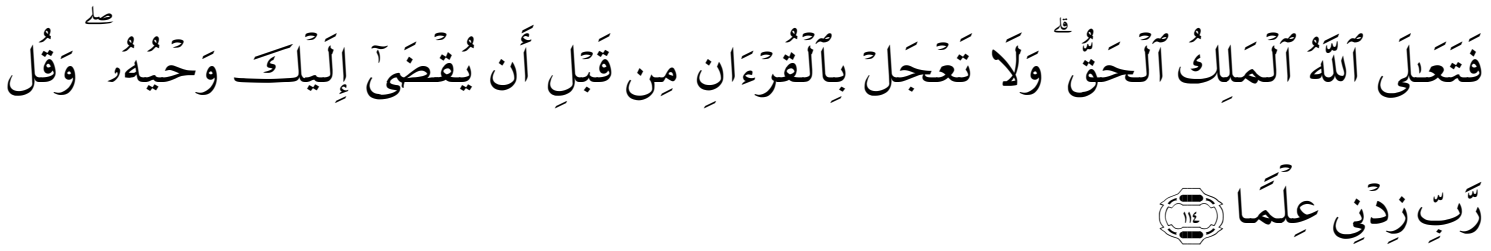

Artinya: Maka Maha Tinggi Allah raja yang sebenar-benarnya, dan janganlah kamu tergesa-gesa membaca Al qur'an sebelum disempurnakan mewahyukannya kepadamu[946], dan Katakanlah: "Ya Tuhanku, tambahkanlah kepadaku ilmu pengetahuan." [Thaha: $20: 114]$

Akan tetapi ilmu ini wajib diiringi dengan amal perbuatan. Ilmu bukan sekedar untuk diketahui, namun dengan ilmu agar bertakwa, beramal shalih, serta menjauhan diri dari perbuatan maksiat dengan landasan takwa kepada Allah Azza wa Jalla . Karenanya dalam firman Allah surat Al-Maidah ayat 91 disebutkan.

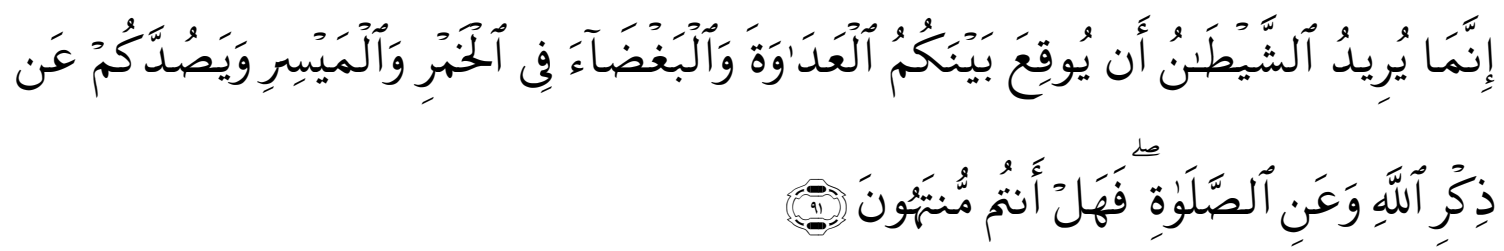

Artinya: Sesungguhnya syaitan itu bermaksud hendak menimbulkan permusuhan dan kebencian di antara kamu lantaran (meminum) khamar dan berjudi itu, dan menghalangi kamu dari mengingat Allah dan sembahyang; Maka berhentilah kamu (dari mengerjakan pekerjaan itu). "Sesungguhnya setan itu bermaksud hendak menimbulkan permusuhan dan kebencian di antara kamu, dan berjudi itu menghalangi kamu dari mengingat Allah dan shalat; maka berhentilah kamu (dari mengerjakan pekerjaan itu)". 
Khamr dan perjudian telah menyebabkan manusia terhalang dari jalan Allah dan bisa menghilangkan akal (kesadaran), sedangkan akal sangat dibutuhkan manusia untuk memahami perintah dan hukum-hukum syari'ah. Dalam ayat ini, setelah Allah Azza wa jalla menjelaskan hukum syar'i dan menjelaskan kewajiban, kemudian seolah-olah Allah Azza wa Jalla hendak menggugah perhatian manusia. Allah Azza wa Jalla berfirman, yang artinya: (maka berhentilah kamu [dari mengerjakan pekerjaan itu]). Mengapa kalian tidak berhenti dari hal-hal yang kalian dilarang darinya, berupa kebiasaan orang-orang Jahiliyah, yaitu khamr dan perjudian? Sedangkan Nabi Shallallahu 'alaihi wa sallam telah bersabda: "Setiap yang memabukkan adalah khamr, dan semua khamr itu haram". Dan bahwasanya, untuk menjaga kebaikan akal, maka syari'at mengharamkan semua yang bisa merusaknya, baik yang maknawi (abstrak) seperti perjudian, nyanyian, memandang sesuatu yang diharamkan, maupun yang bersifat fisik seperti khamr, narkoba serta memberikan sanksi kepada yang melakukannya.(Taimiyyah \& Ash-Shadr, 1993)

\section{d. Menjaga Keturunan (Hifzhun-Nasli).}

Di antara dharûriyyâtul-khams yang dipelihara dan yang dijaga dalam syari'at, yaitu dengan menjaga keturunan. Allah Azza wa Jalla berfirman :

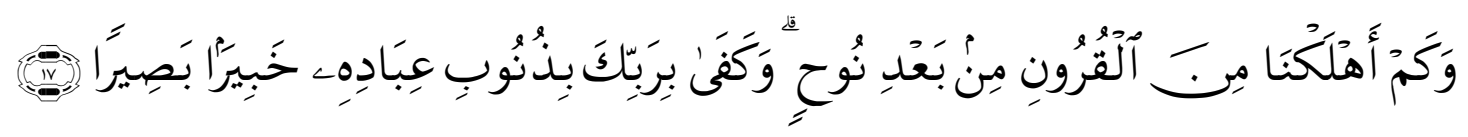

Artinya: dan berapa banyaknya kaum sesudah Nuh telah Kami binasakan. dan cukuplah Tuhanmu Maha mengetahui lagi Maha melihat dosa hamba-hamba-Nya. [Al-Isrâ/17: 32]

Bentuk penjagaan agar manusia menjauhkan diri dari perbuatan zina, maka syari'at membolehkan dan menganjurkan untuk berpoligami, sebagaimana yang terdapat dalam firman Allah Azza wa Jalla menyebutkan.

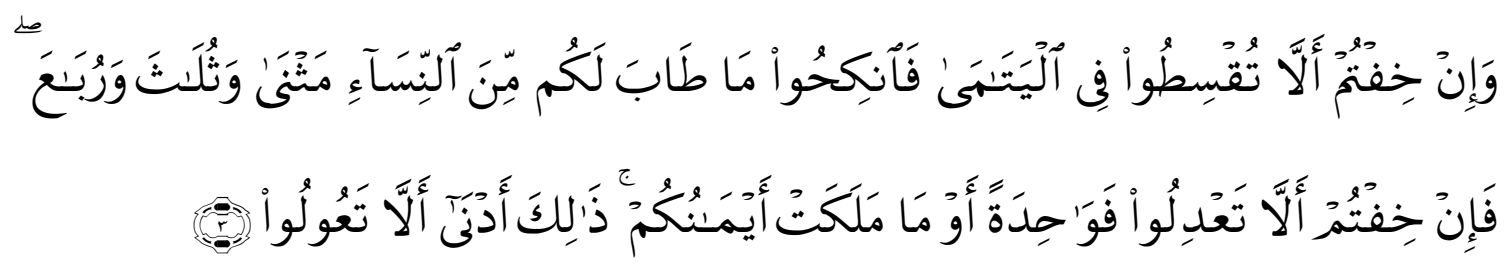

Artinya: dan jika kamu takut tidak akan dapat Berlaku adil terhadap (hak-hak) perempuan yang yatim (bilamana kamu mengawininya), Maka kawinilah wanita-wanita 
(lain) yang kamu senangi : dua, tiga atau empat. kemudian jika kamu takut tidak akan dapat Berlaku adil[265], Maka (kawinilah) seorang saja[266], atau budak-budak yang kamu miliki. yang demikian itu adalah lebih dekat kepada tidak berbuat aniaya. [AnNisâ/4: 3]

Nabi Shallallahu 'alaihi wa sallam juga bersabda : artinya: "Seorang pezina tidak akan melakukan perbuatan zina, sedangkan dia dalam keadaan beriman”. Dalam sebagian riwayat dijelaskan, iman tercerabut darinya. Jika ia berhenti dari berzina, maka keimanannya kembali kepadanya. Semua nash-nash ini untuk menjaga keturunan.

Pemeliharaan keturunan ini, bisa dilihat dari beberapa hal berikut:

a) Anjuran untuk melakukan pernikahan.

b) Persaksian dalam pernikahan.

c) Kewajiban memelihara serta memberikan nafkah kepada anak, termasuk kewajiban dalam memperhatikan pendidikan anak.

d) Mengharamkan nikah dengan seorang pezina.

e) Melarang memutuskan untuk thalaq jika tidak karena terpaksa.

f) Mengharamkan ikhtilâth. (Maqâshidusy-Syarî’ah 'Inda Ibni Taimiyyah, hlm. 473478.)

\section{e. Harta (mal)}

1) Menjaga Harta (Hifzhul-Mali).

Bagian terakhir dari dharuriyâtul-khams yang dijaga oleh syari'at yaitu sesuatu yang menjadi penopang hidup, kesejahteraan serta kebahagiaan, yaitu dengan menjaga harta. Sebagaimana dalam firman Allah Azza wa Jalla:

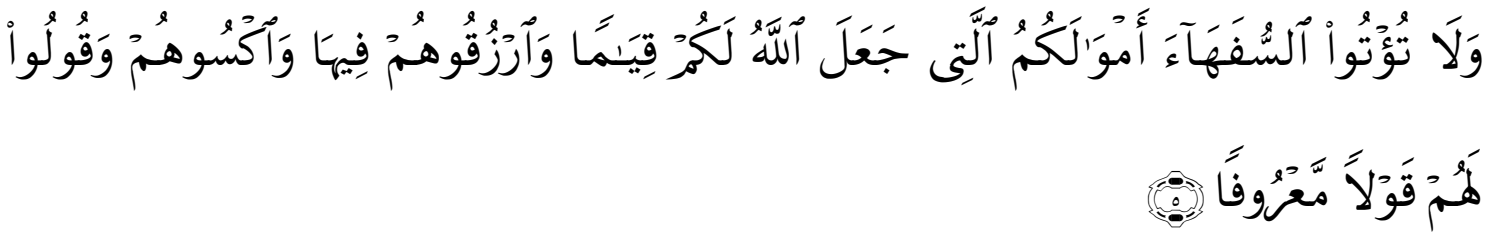

Artinya: dan janganlah kamu serahkan kepada orang-orang yang belum sempurna akalnya[268], harta (mereka yang ada dalam kekuasaanmu) yang dijadikan Allah sebagai pokok kehidupan. berilah mereka belanja dan pakaian (dari hasil harta itu) dan ucapkanlah kepada mereka kata-kata yang baik. [An-Nisâ‘/4 : 5] 
2) Mencari Harta

a) Kerja keras

Dalam hal mencari harta kita disuruh bersungguh-sunggu dan penuh keyakinan tidak pantas jika umat Islam bermalas-malasan dalam bekerja dengan alasan sudah terlalu sibuk beribadah. Mengenai hal ini Allah SWT berfirman dalam QS Al Jumuáh ayat 10 ,

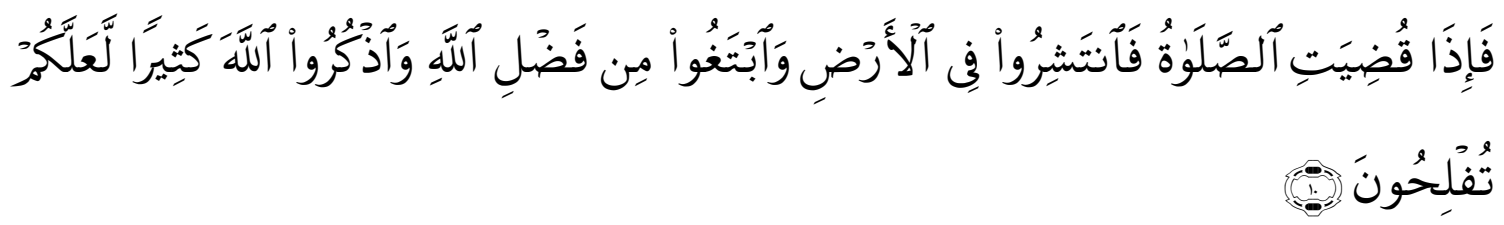
Artinya: apabila telah ditunaikan shalat, Maka bertebaranlah kamu di muka bumi; dan carilah karunia Allah dan ingatlah Allah banyak-banyak supaya kamu beruntung.

Demikian juga dalam QS At-Taubah ayat 105,
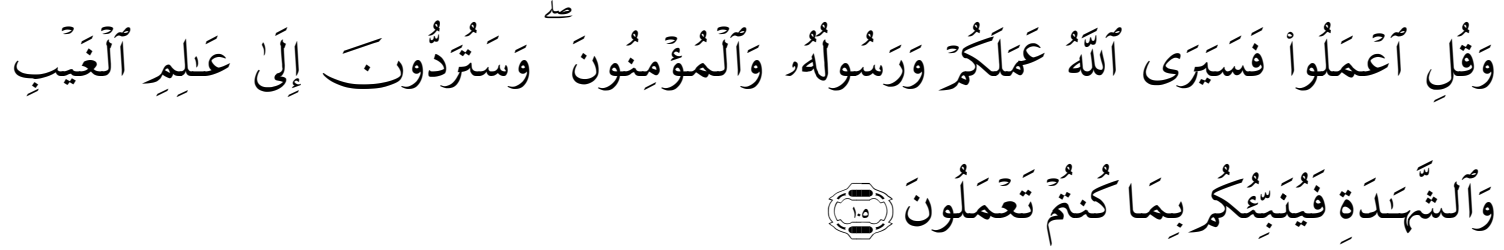

Artinya: dan Katakanlah: "Bekerjalah kamu, Maka Allah dan Rasul-Nya serta orangorang mukmin akan melihat pekerjaanmu itu, dan kamu akan dikembalikan kepada (Allah) yang mengetahui akan yang ghaib dan yang nyata, lalu diberitakan-Nya kepada kamu apa yang telah kamu kerjakan.

Bahkan Rasulullah SAW pun memberikan pujian yang tinggi kepada orang yang mau bekerja keras seperti yang diceritakan dalam sebuah riwayat, pada suatu ketika Rasulullah SAW mengangkat dan mencium tangan seorang lelaki yang sedang bekerja keras. Lantas beliau bersabda: "Bekerja keras dalam usaha mencari nafkah yang halal adalah wajib bagi setiap musalim dan muslimah". Dalam bekerja, Rasulullah SAW juga memberikan tips yang jitu kepada umatnya dengan memerintahkan umatnya untuk bersegera mencari rejeki dipagi hari seperti hadits yang diriwayatkan oleh Thabrani dan Barra' yang artinya: "Berpagi-pagilah dalam mencari rejeki dan kebutuhan, karena pagi hari itu penuh dengan berkah dan keherhasilan."

Dilarang meminta-minta 
"Dari Abu Hurairah r.a., ia berkata: Rasulullah Saw bersabda: Sungguh, seandainya salah seorang di antara kalian mencari kayu bakar dan memikul ikatan kayu itu, maka itu lebih baik, daripada ia meminta-minta kepada seseorang, baik orang itu memberinya ataupun tidak." (HR. Bukhari dan Muslim).

Dalam hadits-hadits yang disebutkan di atas, menunjukkan bahwa bekerja keras pun merupakan perbuatan yang sangat mulia di dalam ajaran Islam. Rasulullah saw memberikan pelajaran menarik tentang pentingnya bekerja. Bekerja merupakan suatu kewajiban, maka tidaklah heran khalifah Umar bin Khaththab suatu ketika pernah menghadang orang yang sedang berada dalam masjid agar keluar dari masjid untuk segera mencari nafkah. Umar tidak suka jika melihat manusia yang sampai siang hari masih tetap asyik berdiam diri dan duduk di masjid, sedangkan mentari sudah menampakkan bersinarnya. Yang dimaksud dengan hadits di atas adalah orang yang bekerja berdasarkan ajaran agama Islam Islam. Bekerja dengan cara yang jujur, halal dan bukan bekerja dengan sesuatu yang diharamkan oleh Allah SWT.

\section{SIMPULAN DAN SARAN}

Nilai-nilai keIslaman nampaknya menjadi salah satu kekuatan yang dominan dalam kebutuhan hidup manusia di abad ini. Kultur masyarakat dapat mempengaruhi antara sesamanya melalui perdagangan, migrasi, dan lain sabagainya. Berbagai kultur budaya masyarakat akan saling melengkapi dan saling berkompetisi dalam kebaikan untuk mempertahankan identitas diri mereka masing-masing. Sebagai konsekwensidari modernitas, menciptakan tantangan baru di setiap identitas manusia, yang kemudian berimplikasi dan juga mengubah system tradisional yang sdah ada, dan menuju era baru yang begitu asing bagi mereka, sehingga adakalanya mereka rentan pada penyakit jiwa, sebab persinggungan pada kultur dan identitas masyarakat membuat masyarakat yang asing tersebut dapat menjadi gagu dalam segala hal, khususnya dengan berbagai kemajuan yang sangat global. 


\section{DAFTAR PUSTAKA}

Aslan. (2017). Pendidikan Remaja Dalam Keluarga di Desa Merabuan, Kalimantan Barat ( Perspektif pendidikan Islam). Al-Banjari, 16(1), 122-135.

Faturrahman, M. (2016). Pendidikan Karakter Dalam Perspektif Pendidikan Islam. Edukasi, 4(1), 1-25.

Hidayati. (2016). Pendidikan Anti Korupsi Tinjauan Perspektif Pendidikan Islam. Hikmah: Jurnal Pendidikan Islam, 5(1), 100-128.

Lusianti, M. (2013). Penerapan Metode Diskusi Syndicate Group Untuk Meningkatkan Aktivitas dan Hasil Belajar Pada Pokok Bahasan Mendeskripsikan Hubungan Antara Kelangkaan Sumber Daya Dengan Kebutuhan Manusia yang Tidak Terbatas. Economic Education Analysis Journal, 2(3), 82-87.

Massie, R. G., \& Kandou, G. D. (2013). Kebutuhan Dasar Kesehatan Masyarakat di Pulau Kecil : Studi Kasus di Pulau Gangga Kecamatan Likupang Barat Kabupaten Minahasa Utara Provinsi Sulawesi Utara. Buletin Penelitian Sistem Kesehatan, $16(2), 1-10$.

Muchtar. (2017). Kebutuhan Dasar Penduduk Daerah Perbatasan: Relevansinya Program Pemberdayaan ( Kajian di Kabupaten Keerom Provinsi Papua berbatasan dengan PNG). Sosio Konsepsia, 11(2), 59-65.

Muryanto, H. (2016). Relevansi Penyajian Bidang Studi Ketrampilan Ketukangan Jenjang Pendidikan Dasar dengan Kebutuhan Masyarakat Industri Kecil Perdesaan. Teknologi Dan Kejujuran, 1(1), 1-10.

Muspiroh, N. (2016). Integrasi Nilai Islam Dalam Pembelajaran IPA ( Perspektif Pendidikan Islam). Jurnal Pendidikan Islam, 28(3), 484-498.

Najahah. (2016). Pemberdayaan Masyarakat Dalam Perspektif Pendidikan Islam. Jurnal Lentera Pendidikan LPPM UM Metro, 14(2), 135-147.

Qodir, Z. (2014). Deradikalisasi Islam dalam Perspektif Pendidikan Agama. Jurnal Pendidikan Islam, 2(1), 85-107.

Rama, H. B. (2017). Akselerasi Pendidikan Tinggi dalam Menjawab Kebutuhan Pendidikan Dasar dan Menengah. Lentera Pendidikan, 14(1), 17-34.

Ridlwan, N. A. (2013). Konsep Pendidikan Karakter Dalam Perspektif Islam. Komunika, 7(1), 1-11. 
Rifai, M. (2016). Peranan Orang Tua Sebagai Wali, Pembimbing, dan Pendidik Pada Perkembangan Anak Dalam Perspektif Pendidikan Agama Islam. Premiere Educandum, 1(1), 1-10.

Siska, Y. (2015). Analisis Kebutuhan Bahan Ajar Sejarah Lokal Lampung Untuk Sekolah Dasar. Mimbar Sekolah Dasar, 2(2), 199-211.

Sukring. (2016). Pendidik dalam Pengembangan Kecerdasan Peserta didik ( Analisis Perspektif Pendidikan Islam). Tadris, 1(1), 57-68.

Sukwadi, R. (2013). Pengembangan Model Integrasi Delphi-AHP-Markov Dalam Perencanaan Kebutuhan Sumber Daya Manusia. Spektrum Industri, 11(2), 229242.

Supriyanto, I. (2012). Kebutuhan Dasar Perumahan Sehat yang Layak dan Teratur. Media of Health Research and Development, 7(1), 1-10.

Taimiyyah, M.-S. 'Inda I., \& Ash-Shadr, M. (1993). Pandangan Bagir ash-Shadr terhadap Pelbagai Aliran Filsafat Dunia (terjemah). Bandung: Al-Mizan.

Tekeng, S. N. Y., \& Alsa, A. (2016). Peranan Kepuasan Kebutuhan Dasar Psikologis dan Orientasi Tujuan Mastery Approach terhadap Belajar Berdasar Regulasi Diri. Jurnal Psikologi, 43(2), 85-106.

Zainuddin, M. R. (2015). Peran Pondok Pesantren Dalam Perspektif Pendidikan Islam. Edukasi, 3(1), 751-764. 